\title{
Artificial Intelligence in a New Context: "Internal" and "External" Factors
}

\author{
Wenceslao J. Gonzalez ${ }^{1}$
}

Published online: 12 September 2017

(C) Springer Science+Business Media B.V. 2017

This special issue analyzes Artificial Intelligence in a new context: AI as a scientific undertaking in the realm of the sciences of design. ${ }^{1}$ This philosophical analysis also takes into account the relations of AI to the Internet as communicative platform and as a hub for information exchange. On the one hand, there is an increasing "scientification" of designs of AI, which includes the combination of new aims, novelty in processes, and innovation in the results; on the other, some developments of AI also have impact on the Internet in several ways (such as those related to machine learning for better translations, the use of algorithms for data economy, the contribution of AI to develop commercial software that can assist medical decisions, or $\mathrm{AI}$ as the basis for new designs concerning audiovisual communication on the Internet). ${ }^{2}$

Following a philosophico-methodological approach within the sciences of the artificial, the analysis of the scientific development of AI and the enhancement of the Internet in scientific terms require taking into account "internal" and "external" factors. ${ }^{3}$ The reason is clear: aims, processes, and results of scientific designs of AI and their consequences for the Internet (especially for the communication sciences)

\footnotetext{
1 This special issue of the journal falls within the sphere of the research project FFI2016-79728-P supported by the Spanish Ministry of Economics, Industry and Competitiveness (AEI). The final version of this paper was prepared at the Centre for Philosophy of Natural and Social Sciences (London School of Economics) during the summer of 2017. I am grateful for the support given by the CPNSS.

2 When there is a repercussion of AI on the Internet as a technological network that runs a motley variety of scientific purposes (communicative, informational, economic, educational, etc.), this impact is often through the use of $\mathrm{AI}$ in those sciences that has a direct relation to the Internet, such as network science or web science. See, for example, the proposal made in Hendler and Berners-Lee (2010).

3 On the sciences directly related to the Internet, see Tiropanis et al. (2015). In addition, the case of data science should be considered in this regard, cf. Cao (2017).
}

Wenceslao J. Gonzalez

wencglez@udc.es

1 University of A Coruña, Campus of Ferrol, Ferrol, Spain 
move along two main lines. On the one hand, there is the concern for the achievement of the goals of AI considered in themselves (i.e., independently of the environment), which can have a repercussion for the development of the Internet; on the other, there is a connection with the setting of the exogenous advancements (social, cultural, economic, political, ecological, etc.), which interact with the achievement of the goals of AI in many ways (especially in the case of the Internet as network of other networks).

Internal factors are, then, those related to language, structure, knowledge, methods, activity, ends, and values of $\mathrm{AI}$ as an expression of the sciences of design (i.e., as a human undertaking that develops designs oriented to specific aims, processes, and results that enlarge human possibilities). This means that AI can be considered from the viewpoint of each element of a science, such as the semantic, logic, epistemological, methodological, ontological, axiological, and ethical components of a scientific activity. ${ }^{4}$ Furthermore, AI can be thought of in terms of the features of the sciences of the artificial, insofar as their amplifications of human possibilities follow a human made synthesis oriented to new aims, processes, and results. 5

Meanwhile, external factors are those connected to the environment (natural, social or artificial) where Artificial Intelligence is developed as part of a scientific undertaking, whose dynamics change over time. In addition to the nexus of AI with its setting in contemporary society, the dynamics of AI includes an interaction between its internal and external factors, which contributes to the historicity of AI. In this regard, this special issue of Minds and Machines is structured along both factors-internal and external-of AI. They appear in different ways in the four parts of this volume, whose papers include the following lines of research:

(I) A characterization of the new context of analysis of Artificial Intelligence, where the sciences of the artificial are the main setting for the analysis. The role of information in AI, in general, and in the case of the Internet is addressed from the angle of the sciences of design. Hence, the paper by Wenceslao J. Gonzalez (University of A Coruña) is focused on the "internal" side. "From Intelligence to Rationality of Minds and Machines in Contemporary Society: The Sciences of Design and the Role of Information" is a paper that deals with the epistemological basis of the artificial intelligence as different from the human intelligence. This distinction has consequences for the development of the sciences of design and the role played by information in them. Thereafter, Maria Jose Arrojo (University of A Coruña) goes more directly into the case of the Internet in her paper "Information and the Internet: An Analysis from the Perspective of the Sciences of the Artificial". She pays attention to the "external" side in the longitudinal and transversal enhancement of the communication sciences, when they are developed through this viewpoint of the sciences of the artificial.

\footnotetext{
${ }^{4}$ On the elements of a science and their philosophical analysis, see Gonzalez (2015, pp. 11-20).

5 The sciences of the artificial are dominantly synthetic, as Herbert Simon maintained, and they are related to how things ought to be in order to attain certain goals (Simon 1996, pp. 4-5). But they also might have analytical components.
} 
(II) New historical and social perspectives on the role of the artificial looks with hindsight through "AI and the Origins of the Functional Programming Language Style", prepared by Mark Priestley (Researcher, University College London). His vision is "internal" and clarifies central aspects of the programming language style in AI. In this regard, the lessons from the past are also useful for a philosophicomethodological viewpoint. Meanwhile, Javier Echeverría and Raúl Tabarés (University of Basque Country) look at the present and future through "Artificial Societies, Cybercities, and Innovation". This paper considers the "external" side of the use of information through the Internet as a motley network. Thus, this "virtual world" is a kind of "third realm" of communication (an artificial environment), which increases human possibilities of communication overcoming the historical steps of the traditional "rural realm" and the subsequent "citizen realm".

(III) Logical and algorithmic developments in Artificial Intelligence: Human intelligence and computational intelligence goes into the logico-methodological basis of the "internal" side of AI. Thus, Luciano Floridi (Oxford University) offers a new logical approach: "The Logic of Design as a Conceptual Logic of Information," where he looks for a conceptual logic of the design of the model of a system. Meanwhile, Giuseppe Primiero (Middlesex University, London) follows a complementary methodological route in his paper "Algorithmic Iteration for Computational Intelligence". It focuses on the theoretical and practical ability of algorithms to design other algorithms of actions aimed at solving tasks that are wellspecified.

(IV) Consequences of new approaches of the artificial for the philosophical analysis goes a step further with "A Constructionist Philosophy of Logic" by Patrick Allo (Free University of Brussels). He insists on the "internal" side with the suggestion of logical systems as conceptual constructions that are the outcome of a design-process. Thus, logic appears as a science of the artificial-in Herbert Simon's sense-which has to do with the interfaces between an "inner" environment-what belongs to the features and organization of the construction-and the "outer" environment, which are the surroundings in which it operates.

Several of these papers were originally presented at a conference on "Artificial Intelligence and Contemporary Society: The Role of Information" held at the University of A Coruña, Campus of Ferrol, on 10 and 11 March 2016. All these topics are connected to the discussions held during those days. Like the XXI Workshop on Philosophy and Methodology of Science (Jornadas sobre Filosofía y Metodología actual de la Ciencia), it enlarges the topics already addressed in the set of volumes previous workshops, which are gathered under the general title of Gallaecia Series. Studies in Contemporary of Philosophy and Methodology of Science.

It is my pleasure to thank the authors of the papers presented here for their efforts to offer a new approach to Artificial Intelligence, taking into account the philosophy of the sciences of the artificial. My special gratitude goes to Luciano Floridi, who was the keynote speaker of the workshop of last year. In addition to him and the other participants at the conference, I am very pleased to thank the editor of this journal-Mariarosaria Taddeo-for her interest in this new contribution to the on 
going discussions on the scientific development of the Artificial Intelligence and its impact on the Internet.

\section{References}

Cao, L. (2017). Data science: A comprehensive overview. ACM Computing Surveys, 50(3), 1-42, art. 43. Gonzalez, W. J. (2015). Philosophico-methodological analysis of prediction and its role in economics. Dordrecht: Springer.

Hendler, J., \& Berners-Lee, T. (2010). From the Semantic Web to social machines: A research challenge for AI on the World Wide Web. Artificial Intelligence, 174(2), 156-161.

Simon, H. A. (1996). The sciences of the artificial (3rd ed.). Cambridge, MA: The MIT Press.

Tiropanis, T., Hall, W., Crowcroft, J., Contractor, N., \& Tassiulas, L. (2015). Network science, web science, and internet science. Communications of ACM, 58(8), 76-82. 